\title{
Multi-Objective Optimal Operation for Steam Power Scheduling Based on Economic and Exergetic Analysis
}

\author{
Yu Huang ${ }^{1}$, Weizhen Hou ${ }^{1}$, Yiran Huang ${ }^{2, *}$, Jiayu $\mathrm{Li}^{1}$, Qixian $\mathrm{Li}^{1}$, Dongfeng Wang ${ }^{1}$ and \\ Yan Zhang ${ }^{1}$ \\ 1 Department of Automation, North China Electric Power University, Baoding 071003, China; \\ huangyufish@ncepu.edu.cn (Y.H.); 2182216069@ncepu.edu.cn (W.H.); 2182216097@ncepu.edu.cn (J.L.); \\ 2192216022@ncepu.edu.cn (Q.L.); wangdongfeng@ncepu.edu.cn (D.W.); zhangyan@ncepu.edu.cn (Y.Z.) \\ 2 Department of Engineering Electronics and Communication Engineering, North China Electric Power \\ University, Baoding 071003, China \\ * Correspondence: hyr_2000@sina.com; Tel.: +86-1378-5216-978
}

Received: 18 January 2020; Accepted: 31 March 2020; Published: 13 April 2020

\begin{abstract}
Steam supply scheduling (SSS) plays an important role in providing uninterrupted reliable energy to meet the heat and electricity demand in both the industrial and residential sectors. However, the system complexity makes it challenging to operate efficiently. Besides, the operational objectives in terms of economic cost and thermodynamic efficiency are usually contradictory, making the online scheduling even more intractable. To this end, the thermodynamic efficiency is evaluated based on exergetic analysis in this paper, and an economic-exergetic optimal scheduling model is formulated into a mixed-integer linear programming (MILP) problem. Moreover, the $\varepsilon$-constraint method is used to obtain the Pareto front of the multi-objective optimization model, and fuzzy satisfying approach is introduced to decide the unique operation strategy of the SSS. In the single-period case results, compared with the optimal scheduling which only takes the economic index as the objective function, the operation cost of the multi-objective optimization is increased by $4.59 \%$, and the exergy efficiency is increased by $9.3 \%$. Compared with the optimal scheduling which only takes the exergetic index as the objective function, the operation cost of the multi-objective optimization is decreased by $19.83 \%$, and the exergy efficiency is decreased by $2.39 \%$. Furthermore, results of single-period and multi-period multi-objective optimal scheduling verify the effectiveness of the model and the solution proposed in this study.
\end{abstract}

Keywords: steam supply scheduling; exergetic analysis; multi-objective; $\varepsilon$-constraint method

\section{Introduction}

As the material basis of human survival and development, energy plays an increasingly important role in promoting social and economic development as well as in improving people's living standards [1]. The energy situation and environmental problems have recently attracted worldwide attention. Steam supply scheduling (SSS) consumes primary energy to provide energy for an enterprise and simultaneously produces a substantial number of pollutants. This paper focuses on optimizing operation of the SSS to reduce the operation cost and improve the thermodynamic efficiency, thus the economic-exergetic operation of the system can be realized [2,3].

Scholars have conducted in-depth studies on the operation optimization of SSS and have made some achievements. Grossman proposed a mixed-integer linear programming (MILP) model framework for utility systems [4], and a mixed-integer nonlinear programming (MINLP) problem based on a successive MILP approach was solved [5]. Based on utility systems modeling, numerous 
scholars have focused on optimal operation strategy so as to achieve cost minimization and energy distribution. In order to reduce operation cost, a model was established which integrated the start and stop of utility operating units under different process requirements [6]. In [7], the multi-period with different electricity or steam demand was introduced into the operation strategy of the utility system, and the optimal choice of units for each period was determined by using the two-stage approach. Based on the linear single-device models in public utility systems, the influence of the change of external electricity price on the system operation scheduling was studied by taking into account the steam equilibrium, fuel supply and devices operation constraints [8]. A multi-period MILP model for byproduct gases, steam and power distribution optimization was proposed in steam power plants, and the experimental results showed that the proposed model could effectively reduce system cost [9]. Given the uncertainty of device efficiency and process demand, a data-driven method was proposed to achieve the tradeoff between optimality and robustness of operational decisions in utility system optimization, and the experiments demonstrated the effectiveness of the method [10,11]. Besides, a method for the simultaneous synthesis of heat exchanger networks and utility systems was presented, and the two-stage algorithm was used to identify the best tradeoff between utility systems and heat exchanger networks costs $[12,13]$. Due to the escalating environmental crisis, several scholars have conducted extensive researches on the environmental issue. Central utility systems with adjoining waste-to-energy networks were integrated to form an ecological friendly energy management system, and the feasibility of the combination of the two networks was demonstrated from environmental and economic perspectives through experiments [14]. By taking into account the impact of pollutants on environment, the utility system consisting of boilers, gas turbines with heat recovery steam generators, ST and CT has been developed [15]. Considering the environmental performance of the entire site utility system, the structural design was optimized to minimize the total annual cost [16]. In addition, the multimodal genetic algorithm was used in the exergoenvironmental analysis of a combined heat and power plant [17]. In general, most studies have focused on the economic and environmental operation that consider energy quantity saving in the SSS, without considering the quality distinction between different energy resources.

In 1953, Rant put forward the concept of exergy, which is a physical quantity that synthesizes the first and the second law of thermodynamics to measure working ability. This concept can focus on the quality and quantity of energy [18-20], which provides a highly efficient method to evaluate the energy efficiency of the system [21-23]. Certain scholars have recently studied the energy system by means of the exergetic analysis. A kind of solid oxide fuel cell integrated with gas and steam trigeneration systems was optimized, and the energy, exergy and economy of the system were analysed in [24]. In addition, the influence of parameter changes on system performance was further studied. An existing CHP system was analysed in terms of energy, exergy and environmental (3E) aspects [25]. In order to analyse the performance and optimize parameter of the geothermal power plant, a system optimization model was formulated to maximize the exergy efficiency, which was solved through the gravitational search algorithm [26]. A study was conducted to examine the energy and exergy performance as well as multi-objective optimization of an exhaust air heat recovery system, which could provide reference for system planning [27]. In [28], considering the total cost, carbon dioxide emission and exergetic destruction, a multi-objective optimization of district heating system was carried out and the Pareto front was obtained with the weighting method. By means of exergy, exergoeconomic and exergoenvironmental analysis, the optimal integration of steam and power system with a steam power plant as the source and a utility system as the sink was investigated, and the experimental results reflected that the integration of steam power plant and utility system is a favorable option [29]. However, most studies have applied exergetic analysis to the performance evaluation and parameter optimization of the energy system, while there are relatively few quality studies on the energy such as heat and electricity in the SSS.

In this paper, exergy is introduced into the operation optimization of SSS. Firstly, the multi-objective mixed-integer linear programming (MOMILP) model of SSS is established by using the exergetic 
analysis method to reduce the operation cost and exergy input for SSS. At the same time, the Pareto front of the multi-objective optimization model is obtained with the $\varepsilon$-constraint approach, and the compromise solution on the Pareto front was acquired with the fuzzy satisfying approach. Finally, the effectiveness of the proposed model and solution method was verified by the results of single-period and multi-period multi-objective optimal scheduling.

This paper is organized as follows: the MOMILP model of SSS is developed in Section 2. In Section 3, the multi-objective operation strategy of SSS is presented to obtain the Pareto front, and a tradeoff is conducted between these different objectives. Case studies are analysed in Section 4, and the conclusion is summarised in Section 5.

\section{Problem Formulation of Multi-objective Optimal Operation of SSS}

The SSS converts primary energy (fuel coal, fuel gas, fuel oil) into secondary energy (electricity, steam and hot water) to provide enterprises with the required process steam, thermal energy and electricity, and its typical structure is illustrated in Figure 1. To realize the economic and efficient operation of the SSS, the mathematical model of each equipment is built and the concept of exergy is adopted to evaluate all types of energy. Subsequently, the MOMILP optimal model of the SSS is formulated.

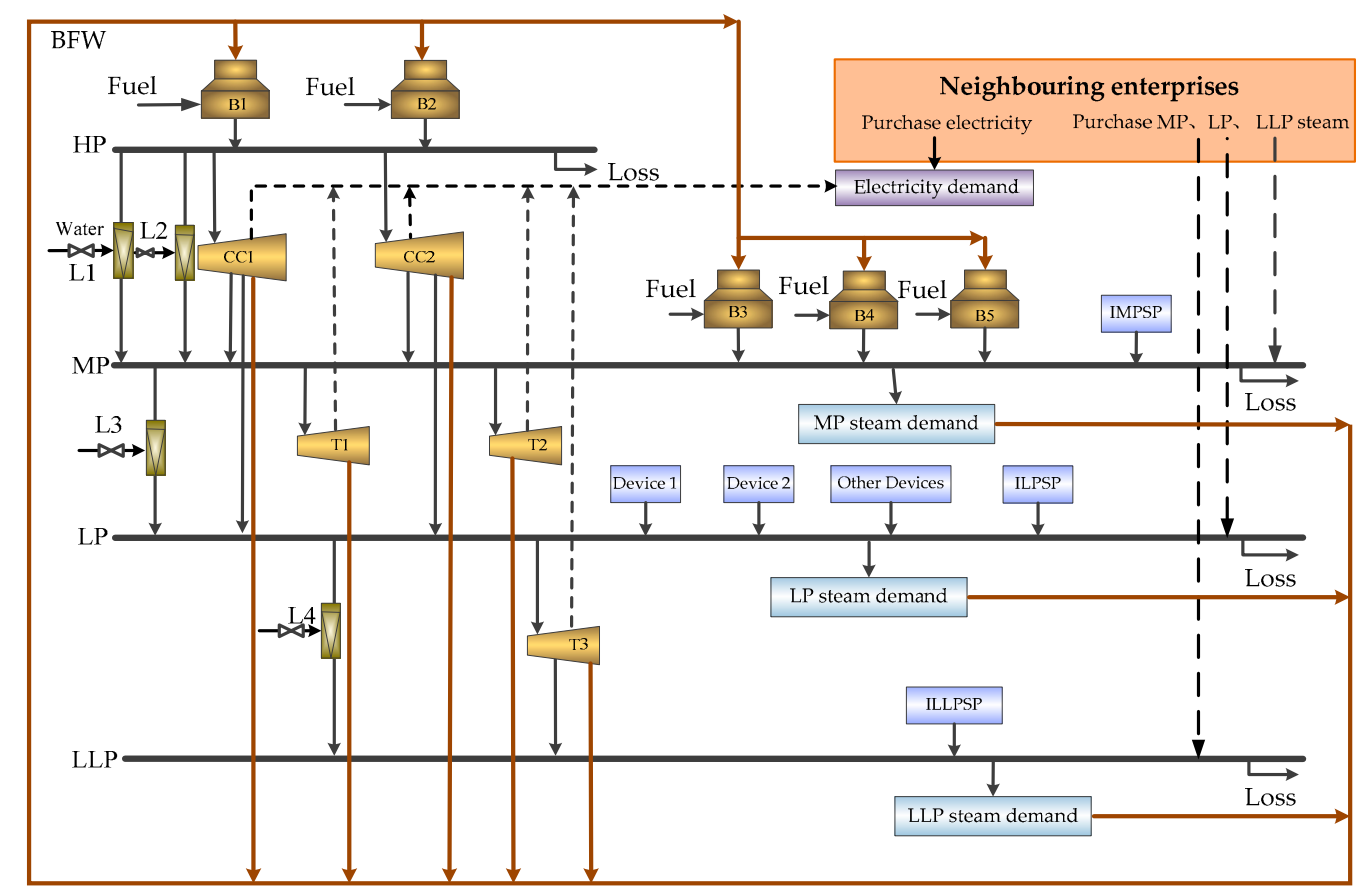

Figure 1. Steam supply scheduling (SSS) of a petrochemical enterprise.

\subsection{Objectives}

\subsubsection{Economic Objective}

Generally, the economic objective of SSS operation is to minimize the total cost of the entire period, including fuel consumption cost, electricity or steam purchase cost, equipment operation and maintenance cost, depreciation cost and equipment start/stop cost. The specific expression is as follows:

$$
\begin{aligned}
f_{1}= & \sum_{B n} \sum_{i} \sum_{t} F_{B n, t, i} p_{i}+\sum_{r} \sum_{t} P S_{r, t} p_{r}+\sum_{t} P E_{t} p_{e} \\
& +\sum_{n} \sum_{t} C M_{n} Y_{n, t}+\sum_{n} \sum_{t} \operatorname{CST}_{n} Z_{n, t}+\sum_{n} \sum_{t} \operatorname{CSP}_{n} Z S_{n, t}
\end{aligned}
$$




\subsubsection{Exergetic Objective}

Exergy represents the maximum amount of useful work that can be obtained from a given form of energy, that is, the quality of energy. For different kinds of energy, the quality of the same quantity of energy is not necessarily the same. Hence, the quality of different energy of the SSS is evaluated with the exergetic analysis method, and then the maximum exergy efficiency can be achieved. Among them, exergy efficiency can be defined as the ratio of the total output exergy to the total input exergy [21], and the formula is as follows:

$$
\psi=\frac{\sum_{t} \dot{E} x_{o u t, t}}{\sum_{t} \dot{E} x_{i n, t}}
$$

Figure 1 shows that the energy types on the load side include electric energy and heat energy, and the input energy includes fossil energy (fuel coal, fuel oil, fuel gas), purchased steam and electricity. Therefore, the load demand exergy and the input exergy of the SSS are expressed as follows:

$$
\left\{\begin{array}{l}
\dot{E} x_{o u t, t}=\dot{E} x_{o u t, t}^{e}+\dot{E} x_{o u t, t}^{h} \\
\dot{E} x_{i n, t}=\dot{E} x_{i n, t}^{c o a l}+\dot{E} x_{i n, t}^{o i l}+\dot{E} x_{i n, t}^{g a s}+\dot{E} x_{i n, t}^{e}+\dot{E} x_{i n, t}^{h}
\end{array}\right.
$$

Fuel coal, fuel oil and fuel gas are all chemical fuels, and their specific exergy is generally expressed by a lower heating value (LHV) and an exergy factor [30,31]. The exergy factors of different types of fuels are slightly different, but basically the same [32]. The exergy in chemical fuels can be expressed by the following formula:

$$
\left\{\begin{array}{l}
\alpha_{i}=\gamma_{i, L H V} \zeta_{i} \\
\dot{E} x_{i n, t}^{i}=\alpha_{i} F_{B n, t, i} / 3.6
\end{array}\right.
$$

The exergy of electricity is equal to electricity because it can be completely converted into work. However, the work done by heat energy is limited by the Carnot factor, and its heat exergy is equal to the work done by the Carnot cycle. Therefore, the heat and electricity exergy of SSS are described as follows:

$$
\begin{gathered}
\dot{E} x_{\text {out }, t}^{h}=\sum_{r}\left(1-\frac{T_{a}}{T_{r}^{h}}\right) D S_{r, t} h_{r} / 3.6 \\
\dot{E} x_{i n, t}^{h}=\sum_{r}\left(1-\frac{T_{a}}{T_{r}^{h}}\right) P S_{r, t} h_{r} / 3.6 \\
\dot{E} x_{o u t, t}^{e}=D E_{t} \\
\dot{E} x_{i n, t}^{e}=P E_{t}
\end{gathered}
$$

The energy demand of SSS is predictable, that is, the total output exergy can be calculated. Therefore, the exergetic objective could be converted from maximum exergy efficiency to minimum exergy input of the SSS. The formula is as follows:

$$
f_{2}=\sum_{t} \dot{E} x_{i n, t}
$$

\subsection{Constraints}

\subsubsection{Device Constraints}

Industrial boilers generally convert the chemical energy in fuel into heat energy, and then transfer this heat energy to water through different heating surfaces, and finally produce the high-pressure (HP) 
or medium-pressure (MP) steam required by the system. The model is represented by Equation (10). Equation (11) indicates that the boiler load should be placed within a certain safety range:

$$
\begin{gathered}
F_{B n, t, i} \gamma_{i, L H V}=a_{B n} Y_{B n, t}+b_{B n} G_{B n, t} \\
G_{B n}^{L} Y_{B n, t} \leq G_{B n, t} \leq G_{B n}^{U} Y_{B n, t}
\end{gathered}
$$

The operation characteristics of a simple ST, including backpressure and $\mathrm{CT}$, can be expressed by the linear relationship between steam intake and power output, and the steam intake and output power of ST should be placed within a certain safety range. The general constraints are detailed as follows:

$$
\begin{gathered}
P_{T n, t}=d_{T n} Y_{T n, t}+e_{T n} G_{T n, i n, t} \\
P_{T n}^{L} Y_{T n, t} \leq P_{T n, t} \leq P_{T n}^{U} Y_{T n, t} \\
G_{T n, i n}^{L} Y_{T n, t} \leq G_{T n, i n, t} \leq G_{T n, i n}^{U} Y_{T n, t}
\end{gathered}
$$

The double extraction CT generates steam with different pressure, and at the same time it can generate the power required to meet the external electricity load. Its output power is related to steam intake, industrial sectors or heating steam extractions. The model generally uses a linear function to represent the relationship among steam intake, adjustable extraction and power of the double extraction CT. It can be described as follows:

$$
\begin{gathered}
P_{c n, t}=g_{c n} G_{c n, i n, t}-\sum_{o j} h_{c n, o j} G_{c n, o j, t}^{o u t}-f_{c n} Y_{c n, t} \\
P_{c n}^{L} Y_{c n, t} \leq P_{c n, t} \leq P_{c n}^{U} Y_{c n, t} \\
G_{c n, i n}^{L} Y_{c n, t} \leq G_{c n, i n, t} \leq G_{c n, i n}^{U} Y_{c n, t} \\
G_{c n, o j}^{o u t, L} Y_{c n, t} \leq G_{c n, o j, t}^{o u t} \leq G_{c n, o j}^{o u t, U} Y_{c n, t}
\end{gathered}
$$

The main function of the pressure reducer and attemperator is to adjust the steam from high temperature and high pressure to the relatively low temperature and low pressure required by the system. The general form of the model is shown in Equation (19) $[10,33]$. For a given steam system, once the steam pressure and temperature of each level steam are specified, the enthalpy $h_{L n, o u t}, h_{L n, i n}$,

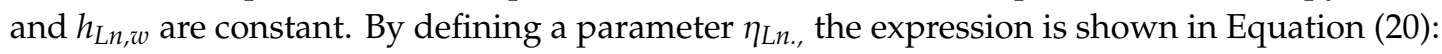

$$
\begin{gathered}
G_{L n, i n, t}=\frac{h_{L n, o u t, t}-h_{L n, w, t}}{h_{L n, i n, t}-h_{L n, w, t}} G_{L n, o u t, t} \\
G_{L n, i n, t}=\eta_{L n} G_{L n, o u t, t}
\end{gathered}
$$

\subsubsection{Balance Constraints}

Electricity balance and steam balance should be considered to meet the energy demand and energy distribution among various energy devices in the SSS should also be considered. Therefore, the steam and electricity balance model are expressed as follows:

$$
\begin{gathered}
D S_{r, t}=P S_{\mathrm{r}, \mathrm{t}}+\sum_{n} G_{B n, t} Y_{B n, t}+\sum_{n} G_{c n, o j, t}^{o u t} Y_{c n, t}+\sum_{n} G_{\mathrm{Ln}, \mathrm{out}, \mathrm{t}} Y_{\mathrm{Ln}, t}-\sum_{n} G_{T n, i n, t} Y_{T \mathrm{n}, t}-\sum_{n} G_{\mathrm{Ln}, \mathrm{in}, \mathrm{Y}} Y_{L n, t}-\text { Loss } r_{r} \\
D E_{t}=P E_{t}+\sum_{n} P_{T n, t} Y_{T \mathrm{n}, t}+\sum_{n} P_{\mathrm{cn}, t} Y_{\mathrm{cn}, t}
\end{gathered}
$$




\subsubsection{Logical Constraints on Device Start and Stop}

Due to the different demand for steam and power in different periods, the equipment is easy to start and stop in the adjacent two periods, thus resulting in the start and stop cost of the equipment. In this study, Equations (23) and (24) are used to represent the start and stop logic of the equipment:

$$
\begin{gathered}
Z_{n, t}=Y_{n, t}-Y_{n, t-1}, Y_{n, 0}=0 \\
Z S_{n, t}=Y_{n, t}-Y_{n, t+1}, Y_{n, t+1}=0
\end{gathered}
$$

In summary, the MOMILP optimal model of SSS can be represented as follows:

$$
\begin{aligned}
\operatorname{min~obj}_{1} & =f_{1}\left(x_{t}, y_{t}\right) \\
\min \mathrm{obj}_{2} & =f_{2}\left(x_{t}, y_{t}\right) \\
\text { subject to } & \left\{\begin{array}{l}
\mathrm{g}\left(x_{t}, y_{t}\right) \leq 0 \\
\mathrm{~h}\left(x_{t}, y_{t}\right)=0 \\
x_{t} \in\left(x^{L}, x^{U}\right) \\
y_{t} \in(0,1)
\end{array}\right.
\end{aligned}
$$

\section{Solution and Decision of the Optimal Condition}

In order to achieve optimal operation of the economy and exergetics of the SSS, this section uses the $\varepsilon$-constraint method to solve the proposed multi-objective problem, so as to obtain the Pareto front. The Pareto curve is used to determine the optimal solution with the fuzzy satisfying approach.

\section{1. $\varepsilon$-Constraint Based Solution}

In the optimization problem of SSS, the two objectives of reducing the operation cost and exergy input are considered to affect each other, that is, it is difficult for both sides to reach the optimal simultaneously. Therefore, the $\varepsilon$-constraint method is used to solve this multi-objective optimal problem. The $\varepsilon$-constraint method preserves one of the objectives in the objective function and transforms the rest of the objective functions into constraints. Thereby the multi-objective optimization problem is transformed into a series of single-objective optimization problems, which can be solved by modifying the value range of the constraints condition step by step. The details are presented as follows:

$$
\begin{aligned}
& \min f_{1} \\
& \left\{\begin{array}{c}
\text { subject to } f_{2} \leq \varepsilon \\
\text { Equations }(1)-(24)
\end{array}\right.
\end{aligned}
$$

where the value of $\varepsilon$ is considered to be expressed by the following equation:

$$
\varepsilon=f_{2, \max }-\left(f_{2, \max }-f_{2, \min }\right)(a-1) /\left(a_{\max }-1\right)
$$

where $a=1,2, \ldots, a_{\max }, a_{\max }$ is the maximum number of cycles; $f_{2, \min }$ and $f_{2, \max }$ are the maximum and minimum values of $f_{2}$ obtained when $f_{2}$ and $f_{1}$ are considered as a single-objective function, respectively. Furthermore, the economic objective is taken as $f_{1}$ as shown in Equation (1) and the exergetic objective as $f_{2}$ as shown in Equation (9) in this paper.

\subsection{Decision based on Fuzzy Satisfying Approach}

To achieve the coordination and unification of the multi-objective of SSS, the fuzzy satisfying approach [34] is introduced to help the operator establish a trade-off between the economic objective and the exergetic objective. The target values of each operation strategy are normalized according to 
(28). Subsequently, the membership function value of each operation strategy is calculated according to (29), and the best operation strategy is selected according to Equation (30):

$$
\begin{gathered}
\mu_{k}^{a}= \begin{cases}1 & f_{k}^{a} \leq f_{k, \min } \\
\frac{f_{k, \max }-f_{k}^{a}}{f_{k, \max }-f_{k, \min }} & f_{k, \min } \leq f_{k}^{a} \leq f_{k, \max } \\
0 & f_{k}^{a} \geq f_{k, \max }\end{cases} \\
\mu^{a}=\min \left(\mu_{1}^{a}, \mu_{2}^{a}\right)
\end{gathered}
$$

To make the fuzzy satisfying approach clearer, a small example is given in Table 1, and the multi-objective optimization strategy selected is scheme 7 , which is the bold part of Table 1. In addition, Figure 2 summarizes the specific process of the multi-objective operation optimization.

Table 1. An example of the fuzzy satisfying approach.

\begin{tabular}{cccccc}
\hline $\boldsymbol{a}$ & $f_{\mathbf{1}}$ & $f_{\mathbf{2}}$ & $\mu_{\mathbf{1}}$ & $\boldsymbol{\mu}_{\mathbf{2}}$ & $\boldsymbol{\mu}^{\max }$ \\
\hline 1 & 57883.09281 & 575814.554 & 1 & 0 & 0 \\
2 & 58242.90797 & 560822.484 & 0.956601 & 0.105264 & 0.105264 \\
3 & 58697.95742 & 545830.368 & 0.901716 & 0.210528 & 0.210528 \\
4 & 59153.00687 & 530838.253 & 0.846831 & 0.315792 & 0.315792 \\
5 & 59608.05632 & 515846.137 & 0.791946 & 0.421056 & 0.421056 \\
6 & 60063.10577 & 500854.021 & 0.73706 & 0.52632 & 0.52632 \\
7 & $\mathbf{6 0 5 6 6 . 3 7 9 4 7}$ & $\mathbf{4 8 5 8 6 1 . 9 0 5}$ & $\mathbf{0 . 6 7 6 3 5 9}$ & $\mathbf{0 . 6 3 1 5 8 4}$ & $\mathbf{0 . 6 3 1 5 8 4}$ \\
8 & 61116.28338 & 470869.789 & 0.610033 & 0.736848 & 0.610033 \\
9 & 61666.18728 & 455877.674 & 0.543707 & 0.842112 & 0.543707 \\
10 & 66174.01862 & 433390.6 & 0 & 1 & 0 \\
\hline
\end{tabular}

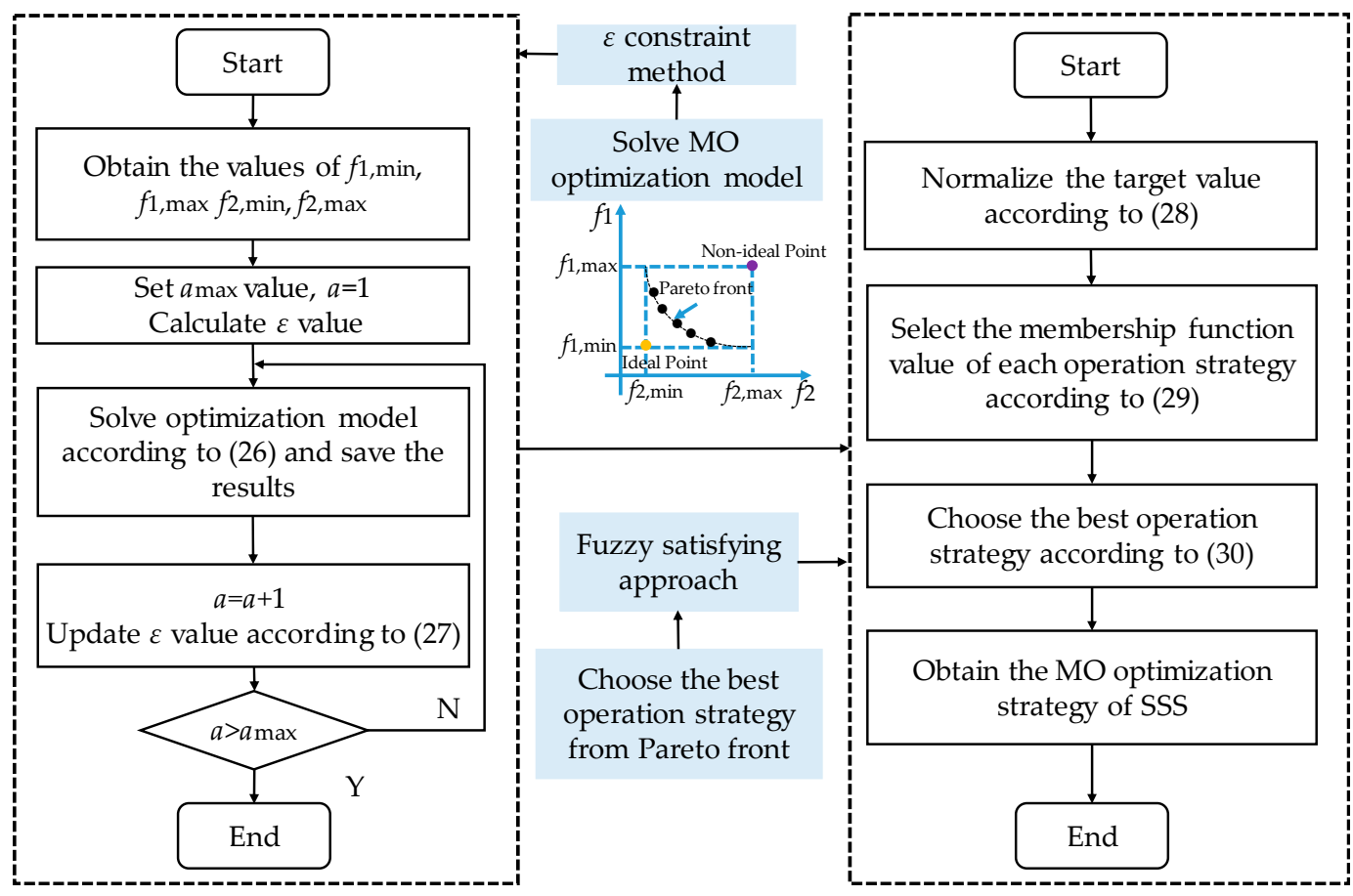

Figure 2. Flowchart of the multi-objective optimization solution.

\section{Case Study}

To verify the effectiveness of the MILP model of SSS with economic and exergetic objectives, the optimal model of single-period and multi-period of SSS are solved and results are analysed in 
this section. Moreover, it is necessary to declare the case studied in this paper does not consider optimization situation of neighbouring enterprises, which is a partial optimization.

\subsection{Case Description}

This study takes the SSS of petrochemical enterprises as an example (Figure 1), which includes four different levels of steam, namely, high-pressure steam ( $\mathrm{HP}, 9.5 \mathrm{MPa}$ and $\left.535^{\circ} \mathrm{C}\right)$, medium pressure steam (MP, 3.5 MPa and $425^{\circ} \mathrm{C}$ ), low-pressure steam (LP, $1 \mathrm{MPa}$ and $300^{\circ} \mathrm{C}$ ) and low and low-pressure steam (LLP, $0.3 \mathrm{MPa}$ and $200^{\circ} \mathrm{C}$ ). B1-B2 are coal-fired boilers that produce HP steam with a blowdown rate of $8 \%$; B3-B5 are dual fuel boilers, which burn oil and gas to produce MP steam. The amount of gas is determined by the processing unit, and the maximum available gas import capacity is $12 \mathrm{t} / \mathrm{h}$. Double extraction CT (CC1, CC2) produces MP and LP steam as well as electric energy. T1 and T2 steam turbines generate power, and T3 produces LLP steam and electric energy. As can be seen from Figure 1, the condensate is recycled and converted into boiler feed water. Furthermore, the minimum value of condensing steam amount of steam turbine is $63 \mathrm{t} / \mathrm{h}$, the maximum value of condensing steam amount is $142 \mathrm{t} / \mathrm{h}$, and the condensing pressure is $5.9 \mathrm{kPa}$. Pressure reducer and attemperator (L1, L2, L3 and L4) can convert high-temperature and high-pressure steam into relatively low-level steam. The study allows the maximum electricity import capacity from neighbouring enterprises of 50,000 kW. The maximum MP steam, LP steam and LLP steam import capacity from neighbouring enterprises of 100, 50 and $50 \mathrm{t} / \mathrm{h}$. The effects of device 1, device 2 and other devices on the system are not considered in this study, and the loss of the system is neither considered, that is, $\operatorname{loss}_{r}=0$. Table 2 indicates the model parameters of boiler and steam turbine. Tables 3 and 4 list the equipment parameters, start/stop costs and equipment operation costs of boilers and ST. Table 5 indicates the unit price of resources. Table 6 shows the parameters of the resource, and Table 7 lists the start and stop time of the equipment.

Table 2. Model parameters of boiler and steam turbine (ST).

\begin{tabular}{cccc}
\hline Parameter & Value & Parameter & Value \\
\hline$a_{B 1}$ & 95.8 & $f_{c 1}$ & -179 \\
$a_{B 2}$ & 95.8 & $f_{c 2}$ & -179 \\
$a_{B 3}$ & 19.47 & $g_{T 3}$ & 73.37 \\
$a_{B 4}$ & 5.818 & $g_{c 1}$ & 252 \\
$a_{B 5}$ & 5.159 & $g_{c 2}$ & 252 \\
$b_{B 1}$ & 0.8488 & $h_{c 1,01}$ & -235 \\
$b_{B 2}$ & 0.8488 & $h_{c 1,02}$ & -102 \\
$b_{B 3}$ & 0.931 & $h_{c 2, o 1}$ & -235 \\
$b_{B 4}$ & 1.021 & $h_{c 202}$ & -102 \\
$b_{B 5}$ & 1.032 & $h_{T 3}$ & -23.3 \\
$d_{T 1}$ & $\eta_{L 1}$ & 0.933 \\
$d_{T 2}$ & -1459 & $\eta_{L 2}$ & 0.933 \\
$e_{T 1}$ & -1650 & $\eta_{L 3}$ & 0.913 \\
$e_{T 2}$ & 86.2 & $\eta_{L 4}$ & 0.923 \\
$f_{T 3}$ & 88.6 & & \\
\hline
\end{tabular}

Table 3. Boiler equipment information.

\begin{tabular}{cccccc}
\hline Boiler & B1 & B2 & B3 & B4 & B5 \\
\hline Rated evaporation $(\mathrm{t} / \mathrm{h})$ & 320 & 320 & 140 & 75 & 65 \\
Minimum evaporation $(\mathrm{t} / \mathrm{h})$ & 160 & 160 & 80 & 35 & 50 \\
Start and stop cost $(¥)$ & 10,000 & 10,000 & 13,000 & 13,000 & 13,000 \\
Equipment operation cost $(¥ / \mathrm{h})$ & 100 & 100 & 200 & 185 & 170 \\
Steam temperature $\left({ }^{\circ} \mathrm{C}\right)$ & 535 & 535 & 425 & 425 & 425 \\
Steam pressure $(\mathrm{MPa})$ & 9.5 & 9.5 & 3.5 & 3.5 & 3.5 \\
Feedwater temperature $\left({ }^{\circ} \mathrm{C}\right)$ & 211.23 & 211.23 & 163 & 163 & 163 \\
Feedwater pressure $(\mathrm{MPa})$ & 15.08 & 15.08 & 3.5 & 3.5 & 3.5 \\
\hline
\end{tabular}


Table 4. Steam turbine equipment information.

\begin{tabular}{|c|c|c|c|c|c|c|c|}
\hline \multirow{2}{*}{ Equipment } & \multirow{2}{*}{$\begin{array}{l}\text { Start and } \\
\text { Stop Cost } \\
\quad(¥)\end{array}$} & \multirow{2}{*}{$\begin{array}{l}\text { Equipment } \\
\text { Operation } \\
\text { Cost }(¥ / \mathrm{h})\end{array}$} & \multicolumn{2}{|c|}{ Power Rating (kW) } & \multirow{2}{*}{$\begin{array}{c}\text { Maximum } \\
\text { Steam Intake } \\
(\mathrm{t} / \mathrm{h})\end{array}$} & \multirow{2}{*}{$\begin{array}{l}\text { Maximum } \\
\text { First } \\
\text { Extraction } \\
\text { Steam }(\mathrm{t} / \mathrm{h})\end{array}$} & \multirow{2}{*}{$\begin{array}{l}\text { Maximum } \\
\text { Second } \\
\text { Extraction } \\
\text { Steam }(t / h)\end{array}$} \\
\hline & & & Maximum & Minimum & & & \\
\hline $\mathrm{CC} 1$ & 12,000 & 200 & 50,000 & 20,000 & 380 & 190 & 180 \\
\hline $\mathrm{CC} 2$ & 12,000 & 200 & 50,000 & 20,000 & 380 & 190 & 180 \\
\hline $\mathrm{T} 1$ & 6000 & 160 & 6500 & 1500 & 85 & - & - \\
\hline $\mathrm{T} 2$ & 6000 & 140 & 6500 & 1500 & 85 & - & - \\
\hline T3 & 6000 & 110 & 6000 & 3500 & 100 & - & - \\
\hline
\end{tabular}

Table 5. The unit price of resources.

\begin{tabular}{ccccccc}
\hline $\begin{array}{c}\text { Fuel Coal } \\
(¥ / \mathbf{t})\end{array}$ & $\begin{array}{c}\text { Fuel Gas } \\
(¥ / \mathbf{t})\end{array}$ & $\begin{array}{c}\text { Fuel Oil } \\
(¥ / \mathbf{t})\end{array}$ & $\begin{array}{c}\text { Electricity } \\
(¥ / \mathbf{k W h})\end{array}$ & $\begin{array}{c}\text { MP Steam } \\
(¥ / \mathbf{t})\end{array}$ & $\begin{array}{c}\text { LP Steam } \\
(¥ / \mathbf{t})\end{array}$ & $\begin{array}{c}\text { LP Steam } \\
(¥ / \mathbf{t})\end{array}$ \\
\hline 750 & 1200 & 3500 & 0.45 & 180 & 135 & 80 \\
\hline
\end{tabular}

Table 6. Parameters of the resource.

\begin{tabular}{ccccccc}
\hline Fuel & $\begin{array}{c}\text { Lower Heating } \\
\text { Value } \mathbf{( k J / k g )}\end{array}$ & $\begin{array}{c}\text { Exergy } \\
\text { Factor }\end{array}$ & $/$ & $\begin{array}{c}\text { Enthalpy } \\
\mathbf{( k J / k g )}\end{array}$ & $\begin{array}{c}\text { Industrial Steam } \\
\text { Production }\end{array}$ & Value (t/h) \\
\hline Coal & 24,440 & 1.08 & MP & 3280.7 & IMPSP & 57 \\
Gas & 32,503 & 1 & LP & 3051.7 & ILPSP & 76.8 \\
Oil & 40,245 & 1.06 & LLP & 2865.9 & ILLPSP & 34.9 \\
& & & Water of $L n$ & 632.2 & & \\
\hline
\end{tabular}

Table 7. Start and stop time of equipment.

\begin{tabular}{ccccccccccc}
\hline Equipment & B1 & B2 & B3 & B4 & B5 & CC1 & CC2 & T1 & T2 & T3 \\
\hline Start time (h) & 10 & 10 & 7.5 & 7.5 & 7.5 & 3.3 & 3.3 & 3.3 & 3.3 & 3.3 \\
Stop time (h) & 10 & 10 & 7.5 & 7.5 & 7.5 & 3.3 & 3.3 & 3.3 & 3.3 & 3.3 \\
\hline
\end{tabular}

\subsection{Single-Period Case}

Table 8 reports the demand for steam and electricity over a single period time, without considering the start and stop costs of the equipment in the economic objective. During the solution process, the maximum number of cycles $n$ in the $\varepsilon$-constraint method is set to 20 .

Table 8. Single-period steam and electricity demands.

\begin{tabular}{cccc}
\hline \multicolumn{3}{c}{ Steam (t/h) } & \multirow{2}{*}{ Electricity $(\mathbf{k W})$} \\
\cline { 1 - 2 } MP & LP & LLP & \\
\hline 180 & 125 & 150 & 64,400 \\
\hline
\end{tabular}

Figure 3 shows the single-period Pareto front for the SSS, the points on it are all optimal values, which can provide different operation strategies for operators. Furthermore, the multi-objective optimal operation strategy can be obtained with the fuzzy satisfying approach, which is the point marked on the Pareto curve in Figure 3. Tables 9 and 10 show the optimal scheduling results of boilers load and purchased resources for SSS. 


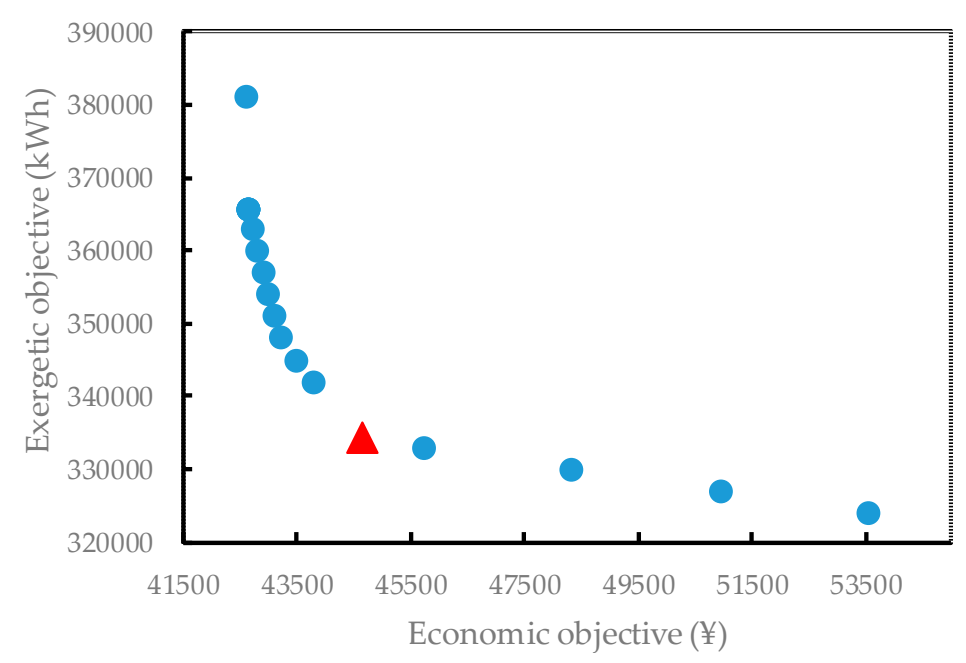

Figure 3. Pareto front of single- period for SSS.

Table 9. Optimal scheduling results of boilers load for SSS.

\begin{tabular}{cccc}
\hline $\begin{array}{c}\text { Boilers Load } \\
(\mathbf{t} / \mathbf{h}) \text { /Situation }\end{array}$ & $\begin{array}{c}\text { Multi-Objective } \\
\text { Operation (Standard) }\end{array}$ & Economic Operation & Exergetic Operation \\
\hline B1 steam production & 320 & 0 & 0 \\
B1 coal consumption & 41.33 & 0 & 0 \\
B2 steam production & 0 & 320 & 247.03 \\
B2 coal consumption & 0 & 41.33 & 34.36 \\
B3 steam production & 0 & 103.00 & 0 \\
B3 oil consumption & 0 & 0 & 0 \\
B3 gas consumption & 0 & 8.55 & 0 \\
B4 steam production & 0 & 0 & 0 \\
B4 oil consumption & 0 & 0 & 0 \\
B4 gas consumption & 0 & 0 & 0 \\
B5 steam production & 0 & 0 & 0 \\
B5 oil consumption & 0 & 0 & 0 \\
B5 gas consumption & 0 & 0 & 0 \\
\hline
\end{tabular}

Table 10. Optimal scheduling results of purchased resources for SSS.

\begin{tabular}{cccc}
\hline $\begin{array}{c}\text { Purchased } \\
\text { Resources/Situation }\end{array}$ & $\begin{array}{c}\text { Multi-Objective } \\
\text { Operation (Standard) }\end{array}$ & Economic Operation & Exergetic Operation \\
\hline PMP steam (t/h) & 21.74 & 0 & 100 \\
PLP steam (t/h) & 0 & 0 & 0 \\
PLLP steam (t/h) & 0 & 0 & 0 \\
PE (kW) & $19,838.62$ & 743.04 & $19,838.62$ \\
\hline
\end{tabular}

Evidently, compared with the multi-objective operation, the energy conversion equipment such as boilers and ST meets the demand for steam and most electricity in the economic operation. Consequently, less steam and electricity are purchased. By contrast, exergetic operation purchases more steam from the neighbouring enterprises. The multi-objective operation establishes a tradeoff between the economic objective and exergetic objective to satisfy the multi-objective optimal operation by coordinating the consumption of different types of energy (fossil energy, heat energy and electric energy).

Table 11 indicates the operation cost, input exergy and exergy efficiency in multi-objective optimization and single-objective optimization. Based on the results of multi-objective optimization, the growth rate of operation cost, input exergy and exergy efficiency in economic operation and exergetic operation are calculated. Results reveal that compared with the multi-objective optimal operation, the operation cost of the economic operation is decreased by $4.59 \%$, while the input exergy 
is increased by $13.97 \%$. On the contrary, for the exergetic operation, its input exergy is decreased by $3.06 \%$, while its operation cost is increased by $19.83 \%$.

Table 11. Comparison of multi-objective optimization results with single-objective optimization results.

\begin{tabular}{cccc}
\hline Situation & Indicator & Value & Growth Rates \\
\hline \multirow{2}{*}{ Multi-objective operation } & Operation cost/¥ & $44,667.83$ & 0 \\
(standard) & Input exergy/kW & 334,216 & 0 \\
& Exergy efficiency/\% & $75.83 \%$ & 0 \\
Economic operation & Operation cost/¥ & $42,615.71$ & $-4.59 \%$ \\
& Input exergy/kW & $380,921.40$ & $13.97 \%$ \\
& Exergy efficiency/\% & $66.53 \%$ & $-9.3 \%$ \\
Exergetic operation & Operation cost/¥ & $53,526.94$ & $19.83 \%$ \\
& Input exergy/kW & $323,989.8$ & $-3.06 \%$ \\
& Exergy efficiency/\% & $78.22 \%$ & $2.39 \%$ \\
\hline
\end{tabular}

Compared with SSS optimal scheduling which only takes economic or exergetic as the objective function, from the above calculated data, it can see that the multi-objective operation can comprehensively consider energy efficiency from the point of view of economic and exergetic, make a tradeoff between the economic index and exergetic index, and pay attention to the quality and quantity of energy simultaneously, so as to achieve the purpose of reducing cost and increasing efficiency. Furthermore, this paper is in line with the sustainable energy development strategy of the world today.

\subsection{Multi-Period Case}

A multi-period case is established in this section to further verify the effectiveness of the proposed multi-objective model and solution method. The multi-period model includes six periods, each with a duration of $720 \mathrm{~h}$, which is consistent with the solution method and the $\varepsilon$-constraint parameter setting in Section 4.2. Table 12 indicates the steam and electricity demands of the six periods. The optimal scheduling results are detailed as follows.

Table 12. Multi-period steam and electricity demands.

\begin{tabular}{ccccc}
\hline \multirow{2}{*}{ Period } & \multicolumn{3}{c}{ Steam (t/h) } & \multirow{2}{*}{ Electricity (kW) } \\
\cline { 2 - 4 } & MP & LP & LLP & \\
\hline 1 & 180 & 125 & 150 & 64,400 \\
2 & 350 & 165 & 75 & 73,700 \\
3 & 320 & 185 & 60 & 85,700 \\
4 & 250 & 200 & 95 & 58,700 \\
5 & 200 & 175 & 105 & 67,600 \\
6 & 335 & 300 & 120 & 78,300 \\
\hline
\end{tabular}

Figure 4 depicts the steam distribution among the equipment. It can be seen that under the premise of fully considering the steam purchase, the boiler and ST jointly produce steam, and the system supplements the regulation of pressure reducer and attemperator, thus the integrated operation of steam production and supply at all levels can be realized. 


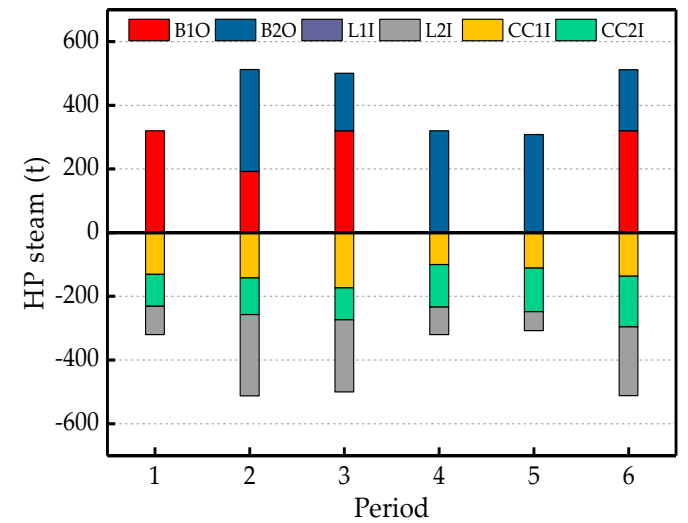

(a)

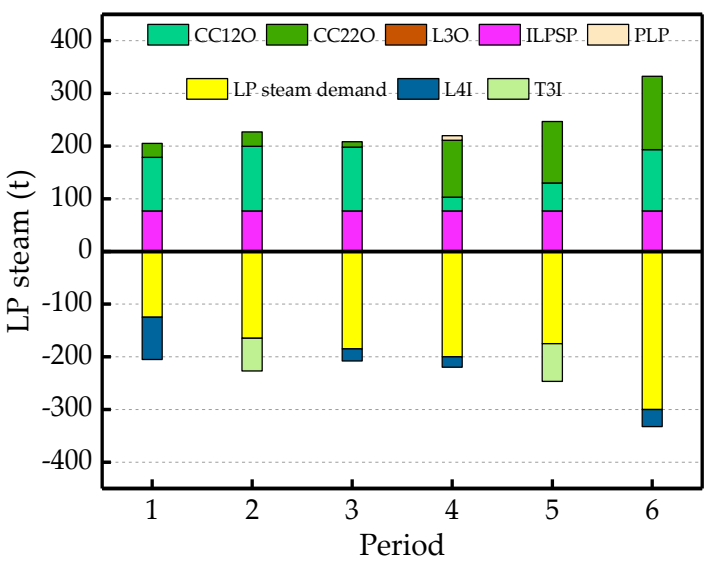

(c)

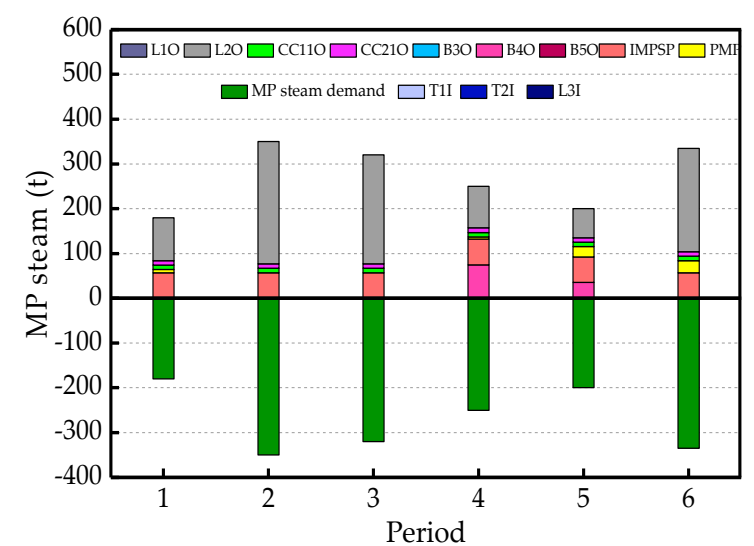

(b)

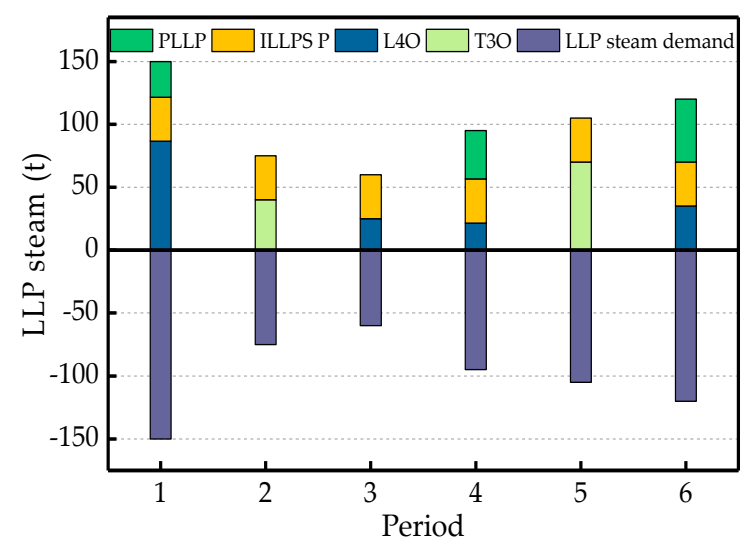

(d)

Figure 4. Optimal scheduling results for steam: (a) high-pressure steam; (b) medium pressure steam; (c) low-pressure steam; (d) low and low-pressure steam. (I, O indicate input and output of equipment, respectively.).

Table 13 shows the optimal scheduling results of the start and stop of multi-period operation equipment. Figure 5 describes the optimal scheduling results of fuel consumed in the system. Evidently, changes in steam and electricity demand lead to the inevitably start and stop of equipment, thus changing fuel consumption. Due to the relative high steam and electricity demand compared with other periods, the B1 and B2 are in operation in periods 2, 3 and 6. Furthermore, since the MP steam demand of period 1 is lower than that of periods 4 and 5, boilers producing MP steam are closed in period 1. Moreover, considering that the energy of the system is converted from the HP steam generated by B1 and B2, a large amount of coal is consumed.

Table 13. Optimal scheduling results of start/stop of multi-period operation equipment.

\begin{tabular}{cllllll}
\hline Equipment/Period & $\mathbf{1}$ & $\mathbf{2}$ & $\mathbf{3}$ & $\mathbf{4}$ & $\mathbf{5}$ & $\mathbf{6}$ \\
\hline B1 & 1 & 1 & 1 & 0 & 0 & 1 \\
B2 & 0 & 1 & 1 & 1 & 1 & 1 \\
B3 & 0 & 0 & 0 & 0 & 0 & 0 \\
B4 & 0 & 0 & 0 & 1 & 1 & 0 \\
B5 & 0 & 0 & 0 & 0 & 0 & 0 \\
CC1 & 1 & 1 & 1 & 1 & 1 & 1 \\
CC2 & 1 & 1 & 1 & 1 & 1 & 1 \\
T1 & 0 & 0 & 0 & 0 & 0 & 0 \\
T2 & 0 & 0 & 0 & 0 & 0 & 0 \\
T3 & 0 & 1 & 0 & 0 & 1 & 0 \\
\hline
\end{tabular}




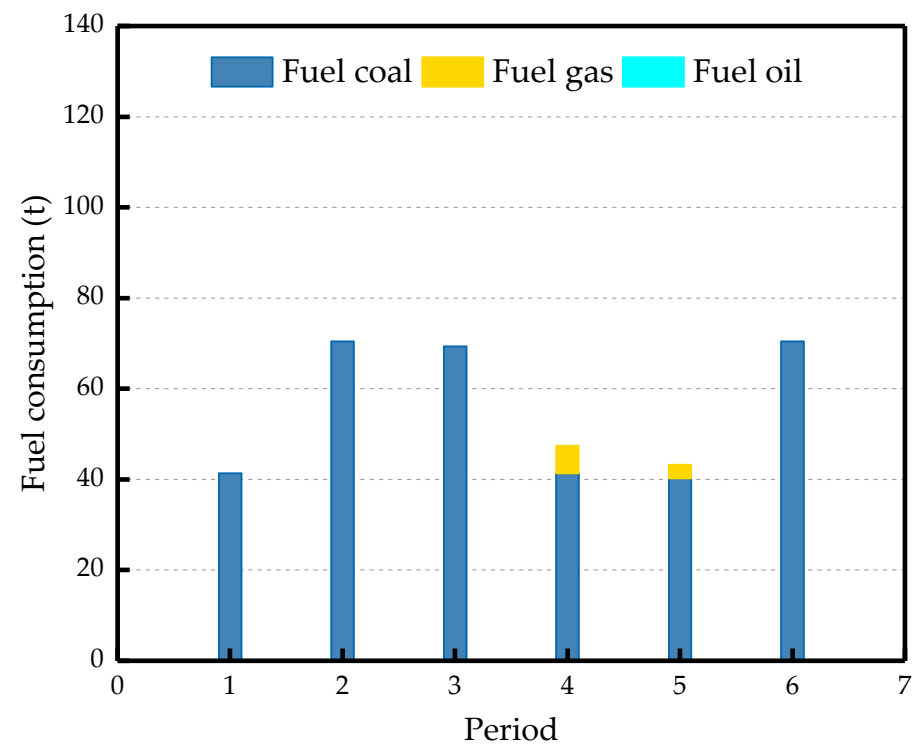

Figure 5. Optimal scheduling results for fuel.

Figure 6 shows the optimal scheduling results of electricity. Under the premise of purchasing electricity (Figure 6 PE), it can be observed that the coordinated operation of T1, T2, T3, CC1 and CC2 can meet the electricity demand. Besides, T1 and T2 are stopped in each period and double extraction $\mathrm{CT}$ is used more frequently during the operation process. On the one hand, this is because CC1 and CC2 can satisfy most of the electricity demand. Moreover, $\mathrm{CC} 1$ and $\mathrm{CC} 2$ can generate electricity and produce both MP and LP steam to meet the steam demand by consuming HP steam. On the other, $\mathrm{T} 1$ and T2 only generate electricity. In order to save operation costs, it is not necessary to maintain the operation of all units. In addition, T3 is used more frequently than T1 and T2, partly because T3 can generate electricity and LLP steam simultaneously. On the other hand, it can be seen from Table 4 that the operation cost of T3 is lower than that of T1 and T2. Accordingly, this operation strategy can save economic costs. Furthermore, in order to balance both economic and exergetic objectives, the system neither over purchases energy, nor blindly consumes chemical fuel to meet the electricity demand, thus realizing the primary energy saving and improving the thermodynamic efficiency of the system in multi-period operation.

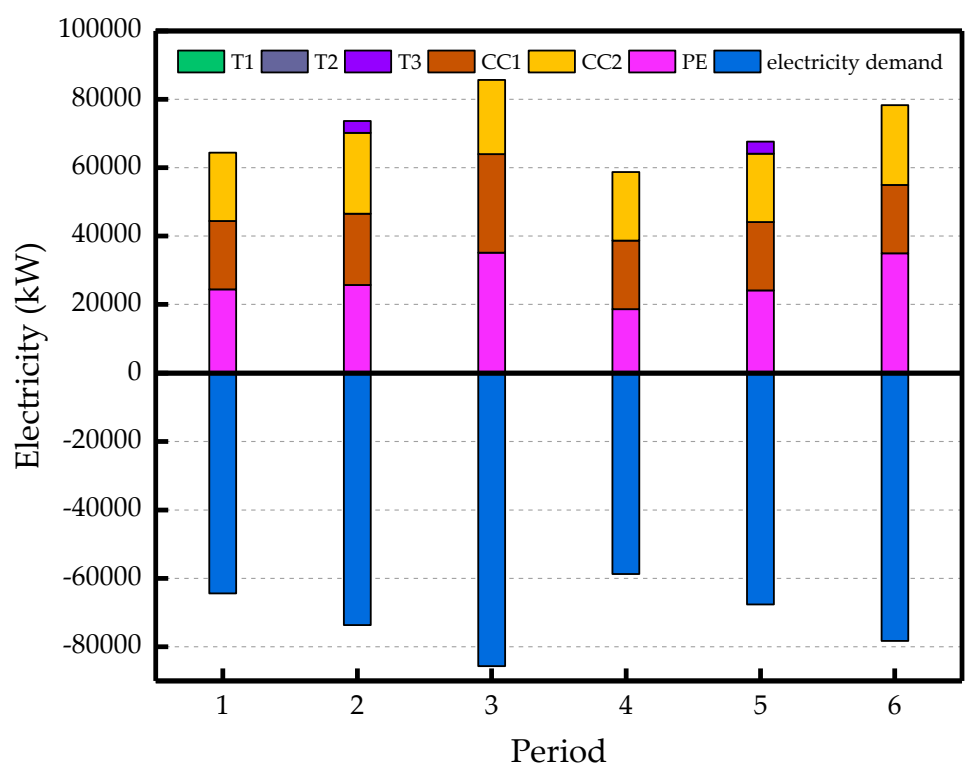

Figure 6. Optimal scheduling results for electricity. 
Therefore, the multi-period case study in this section can provide guiding significance for the actual operating system, and the corresponding unit output plan can be made from the two aspects of system economy and thermodynamic efficiency. Furthermore, this study can help reduce greenhouse gas emissions and improve the thermodynamic efficiency under the premise of meeting the power and thermal demand of enterprises.

\section{Conclusions}

In order to achieve a good balance between enhancing energy efficiency and reducing system cost, this paper adopts the exergetic analysis method in thermodynamics to evaluate the effective energy contained in different kinds of energy. At the same time, the exergetic objective function is built. Considering the cost of electricity and steam, combined with the mathematical model of each equipment, an SSS optimal model based on economic index and exergetic index is further built. Utilizing the $\varepsilon$-constraint method to obtain the Pareto front of multi-objective optimization problems, the fuzzy satisfying approach is introduced to determine the optimal operation strategy. Taking the single-period operation as an example, it can be seen that the multi-objective optimization operation strategy can consider the economic and exergetic of the system by comparing with the single- objective optimization results. Meanwhile, the single-objective optimization only takes the economic or exergetic index as the objective function. Moreover, it can be verified by the results of multi-period scheduling that the multi-objective model and solution is effective. In addition, to deal with the multi-objective problem, the fuzzy satisfying approach is introduced to obtain the optimal results. However, the optimal results may rely on the fuzzy satisfying approach. Therefore, to get better multi-objective optimal results, our future work will focus on the effectiveness of various multi-objective optimal methods.

Author Contributions: Y.H. (Yiran Huang) supervised and revised the manuscript from the initial submission to the final version. Y.H. (Yu Huang) formulated the research problem; Y.H. (Yu Huang), W.H. and Q.L. proposed the mathematical model and solution scheme; W.H. and J.L. wrote the code and solved the optimization model; D.W. and Y.Z. revised the manuscript. All of the authors were involved in writing this paper. All authors have read and agreed to the published version of the manuscript.

Funding: This research was supported by 'the Fundamental Research Funds for the Central Universities 2018MS093 and 2019MS099'.

Conflicts of Interest: The authors declare no conflict of interest.

\section{Nomenclature}

$\begin{array}{ll}a_{B n}, b_{B n} & \text { model comodel coefficients of } B n \\ C M_{n} & \text { operation and maintenance of equipment (¥) } \\ C S T_{n} & \text { start cost of equipment } ¥) \\ C S P_{n} & \text { stop cost of equipment (¥) } \\ D E_{t} & \text { demand electricity of the SSS }(\mathrm{kW}) \\ D S_{r, t} & \text { demand steam of the SSS (t/h) } \\ d_{T n}, e_{T n} & \text { model coefficients of Tn } \\ \dot{E} x_{o u t, t} & \text { exergy output of SSS }(\mathrm{kW}) \\ \dot{E} x_{i n, t} & \text { exergy input of SSS }(\mathrm{kW}) \\ \dot{E} x_{\text {out }, t}^{e} & \text { electricity exergy output }(\mathrm{kW}) \\ \dot{E} x_{o u t, t}^{h} & \text { heat exergy output }(\mathrm{kW}) \\ \dot{E} x_{i n, t}^{c o a l} & \text { fuel coal exergy input }(\mathrm{kW}) \\ \dot{E} x_{i n, t}^{\text {cil }} & \text { fuel oil exergy input }(\mathrm{kW}) \\ \dot{E} x_{i n, t}^{\text {gas }} & \text { fuel gas exergy input }(\mathrm{kW}) \\ \dot{E} x_{i n, t}^{e} & \text { electricity exergy input }(\mathrm{kW}) \\ \dot{E} x_{i n, t}^{h} & \text { heat exergy input }(\mathrm{kW}) \\ F_{B n, t, i} & \text { fuel consumed by the boiler }(\mathrm{t} / \mathrm{h})\end{array}$




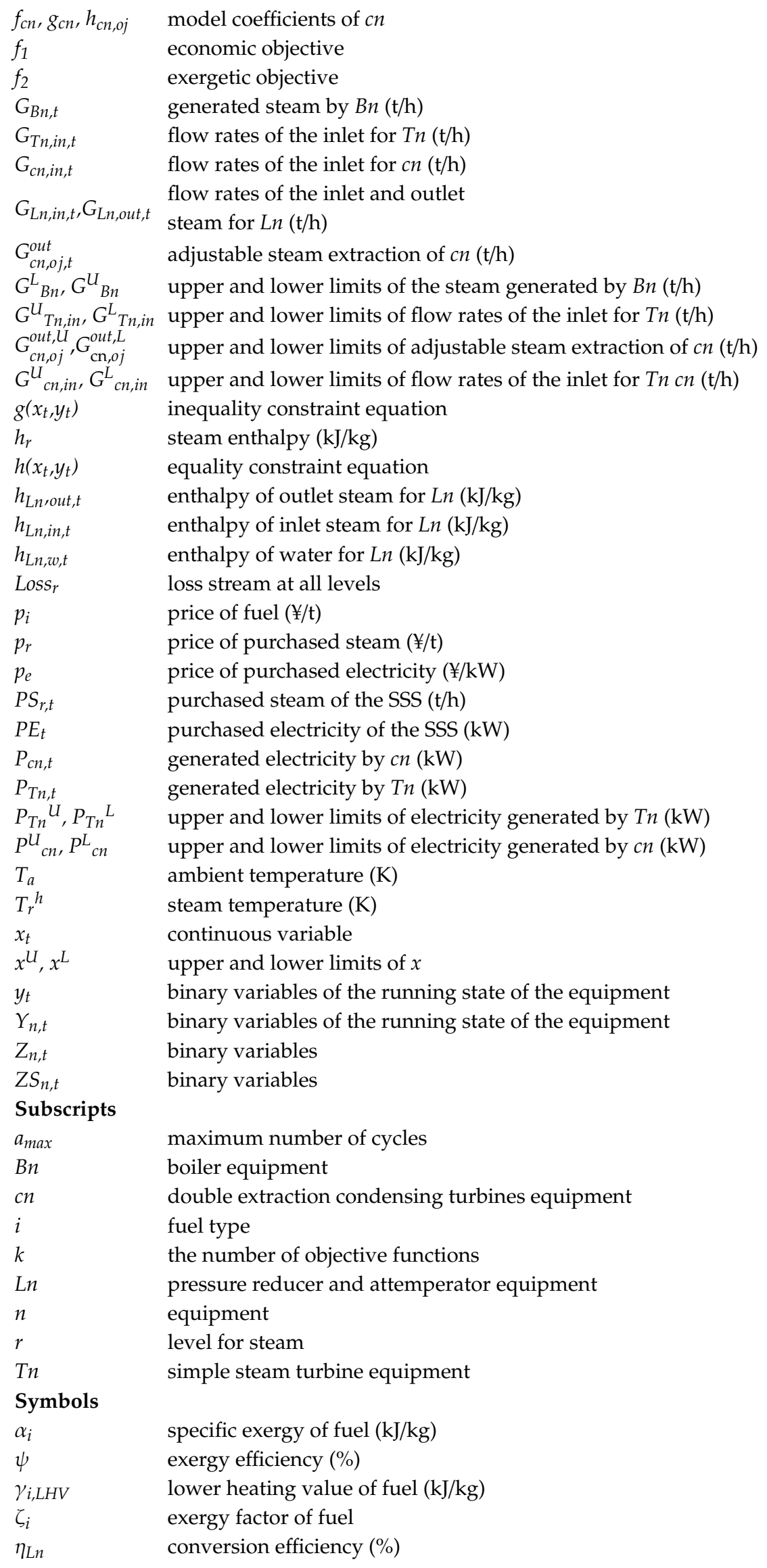




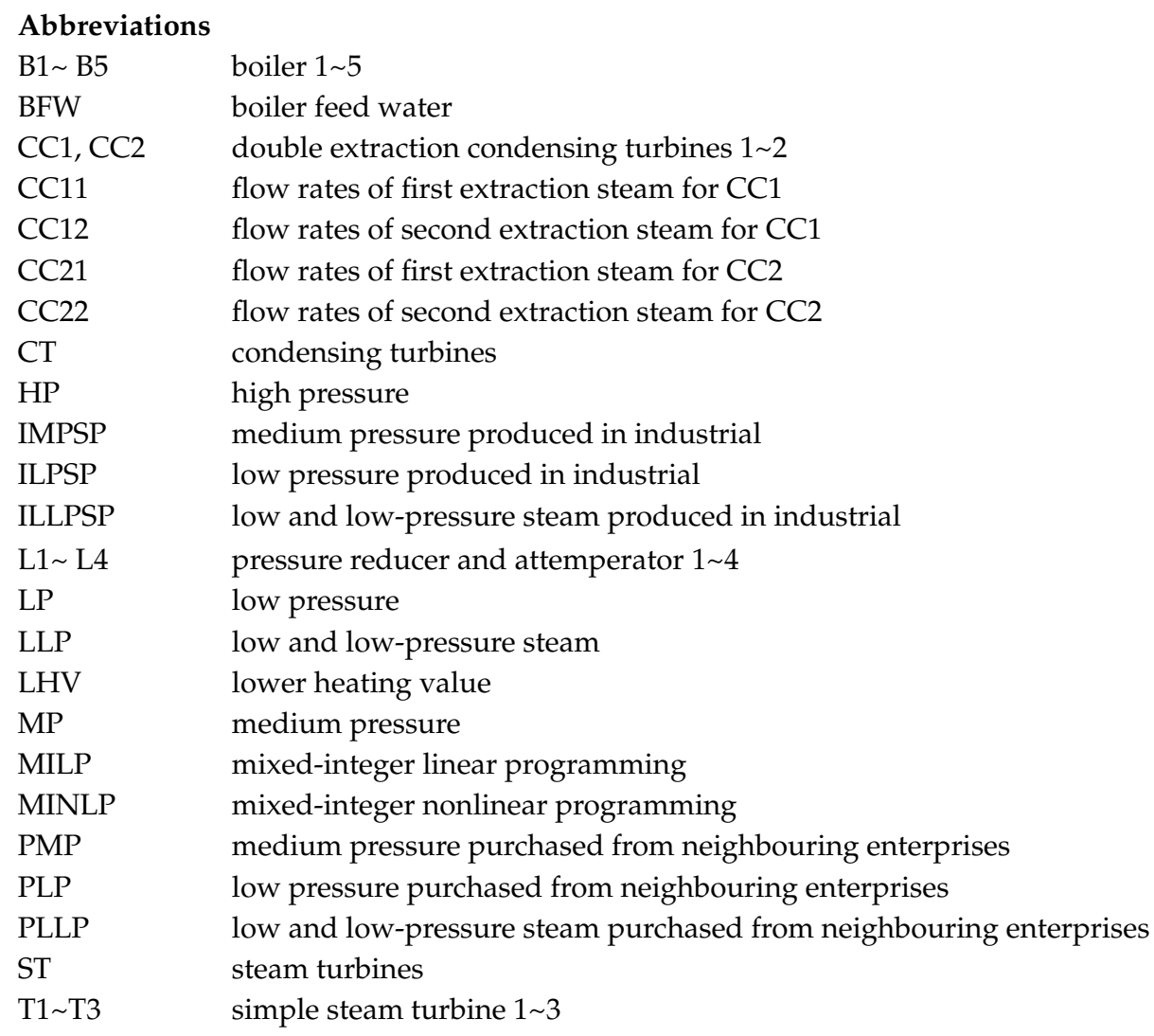

\section{References}

1. Luo, X.; Zhang, B.; Chen, Y.; Mo, S. Operational planning optimization of steam power plants considering equipment failure in petrochemical complex. Appl. Energy 2013, 112, 1247-1264. [CrossRef]

2. Luo, X.; Zhang, B.; Chen, Y.; Mo, S. Modeling and optimization of a utility system containing multiple extractions steam turbines. Energy 2011, 36, 3501-3512. [CrossRef]

3. Douglas, T.; Big-Alabo, A. A generic algorithm of sustainability (GAS) function for industrial complex steam turbine and utility system optimisation. Energy 2018, 164, 881-897. [CrossRef]

4. Iyer, R.R.; Grossmann, I.E. Synthesis and operational planning of utility systems for multiperiod operation. Comput. Chem. Eng. 1998, 22, 979-993. [CrossRef]

5. Varbanov, P.S.; Doyle, S.; Smith, R. Modelling and optimization of utility systems. Chem. Eng. Res. Des. 2004, 82, 561-578. [CrossRef]

6. Velasco-Garcia, P.; Varbanov, P.S.; Arellano-Garcia, H.; Wozny, G. Utility systems operation: Optimisation-based decision making. Appl. Therm. Eng. 2011, 31, 3196-3205. [CrossRef]

7. Iyer, R.R.; Grossmann, I.E. Optimal multiperiod operational planning for utility systems. Comput. Chem. Eng. 1997, 21, 787-800. [CrossRef]

8. Tao, T.; Ye, J.; Beixing, W. Modeling and optimization for steam power system in petrochemical plant under steam mutual supply condition. Energy Conserv. Emiss. Reduct. Pet. Petrochem. Ind. 2011, 2, 10-15.

9. Zeng, Y.; Xiao, X.; Li, J.; Sun, L.; Floudas, C.A.; Li, H. A novel multi-period mixed-integer linear optimization model for optimal distribution of byproduct gases, steam and power in an iron and steel plant. Energy 2018, 143, 881-899. [CrossRef]

10. Zhao, L.; You, F. A data-driven approach for industrial utility systems optimization under uncertainty. Energy 2019, 182, 559-569. [CrossRef]

11. Sun, L.; Shen, J.; Hua, Q.; Lee, K.Y. Data-driven oxygen excess ratio control for proton exchange membrane fuel cell. Appl. Energy 2018, 231, 866-875. [CrossRef] 
12. Martelli, E.; Elsido, C.; Mian, A.; Marechal, F. Synthesis of Heat Exchanger Networks and Utility Systems: Sequential Initialization Procedure and Simultaneous MINLP Algorithm. In Computer Aided Chemical Engineering; Elsevier: London, UK, 2016; Volume 38, pp. 1449-1454.

13. Martelli, E.; Elsido, C.; Mian, A.; Marechal, F. MINLP model and two-stage algorithm for the simultaneous synthesis of heat exchanger networks, utility systems and heat recovery cycles. Comput. Chem. Eng. 2017, 106, 663-689. [CrossRef]

14. Hwangbo, S.; Sin, G.; Rhee, G.; Yoo, C. Development of an integrated network for waste-to-energy and central utility systems considering air pollutant emissions pinch analysis. J. Clean. Prod. 2020, 252, 119746. [CrossRef]

15. Sun, L.; Gai, L.; Smith, R. Site utility system optimization with operation adjustment under uncertainty. Appl. Energy 2017, 186, 450-456. [CrossRef]

16. Walmsley, T.G.; Jia, X.; Varbanov, P.S.; Klemeš, J.J.; Wang, Y. Total Site Utility Systems Structural Design Considering Environmental Impacts. In Computer Aided Chemical Engineering; Elsevier: London; UK, 2018; Volume 43, pp. 1305-1310.

17. Ahmadi, P.; Dincer, I. Exergoenvironmental analysis and optimization of a cogeneration plant system using Multimodal Genetic Algorithm (MGA). Energy 2010, 35, 5161-5172. [CrossRef]

18. Sevinchan, E.; Dincer, I.; Lang, H. Energy and exergy analyses of a biogas driven multigenerational system. Energy 2019, 166, 715-723. [CrossRef]

19. Morosuk, T.; Tsatsaronis, G. Advanced exergy-based methods used to understand and improve energy-conversion systems. Energy 2019, 169, 238-246. [CrossRef]

20. Elhelw, M.; Al Dahma, K.S.; el Hamid Attia, A. Utilizing exergy analysis in studying the performance of steam power plant at two different operation mode. Appl. Therm. Eng. 2019, 150, 285-293. [CrossRef]

21. Sansaniwal, S.K.; Sharma, V.; Mathur, J. Energy and exergy analyses of various typical solar energy applications: A comprehensive review. Renew. Sustain. Energy Rev. 2018, 82, 1576-1601. [CrossRef]

22. Noroozian, A.; Mohammadi, A.; Bidi, M.; Ahmadi, M.H. Energy, exergy and economic analyses of a novel system to recover waste heat and water in steam power plants. Energy Convers. Manag. 2017, 144, 351-360. [CrossRef]

23. Wang, J.; Chen, Y.; Lior, N.; Li, W. Energy, exergy and environmental analysis of a hybrid combined cooling heating and power system integrated with compound parabolic concentrated-photovoltaic thermal solar collectors. Energy 2019, 185, 463-476. [CrossRef]

24. Ehyaei, M.A.; Rosen, M.A. Optimization of a triple cycle based on a solid oxide fuel cell and gas and steam cycles with a multiobjective genetic algorithm and energy, exergy and economic analyses. Energy Convers. Manag. 2019, 180, 689-708. [CrossRef]

25. Ahmadi, G.; Toghraie, D.; Akbari, O. Energy, exergy and environmental (3E) analysis of the existing CHP system in a petrochemical plant. Renew. Sustain. Energy Rev. 2019, 99, 234-242. [CrossRef]

26. Özkaraca, O.; Keçebaş, A. Performance analysis and optimization for maximum exergy efficiency of a geothermal power plant using gravitational search algorithm. Energy Convers. Manag. 2019, 185, 155-168. [CrossRef]

27. Shahsavar, A.; Khanmohammadi, S. Feasibility of a hybrid BIPV/T and thermal wheel system for exhaust air heat recovery: Energy and exergy assessment and multi-objective optimization. Appl. Therm. Eng. 2019, 146, 104-122. [CrossRef]

28. Dorotić, H.; Pukšec, T.; Duić, N. Economical, environmental and exergetic multi-objective optimization of district heating systems on hourly level for a whole year. Appl. Energy 2019, 251, 113394. [CrossRef]

29. Manesh, M.K.; Navid, P.; Baghestani, M.; Abadi, S.K.; Rosen, M.A.; Blanco, A.M.; Amidpour, M. Exergoeconomic and exergoenvironmental evaluation of the coupling of a gas fired steam power plant with a total site utility system. Energy Convers. Manag. 2014, 77, 469-483. [CrossRef]

30. Huang, Y.; Li, S.; Ding, P.; Zhang, Y.; Yang, K.; Zhang, W. Optimal operation for economic and exergetic objectives of a multiple energy carrier system considering demand response program. Energies 2019, 12, 3995. [CrossRef]

31. Kotas, T.J. The Exergy Method of Thermal Plant Analysis; Elsevier: London, UK, 2013.

32. Ramirez-Elizondo, L.M.; Paap, G.C.; Ammerlaan, R.; Negenborn, R.R.; Toonssen, R. On the energy, exergy and cost optimisation of multi-energy-carrier power systems. Int. J. Exergy 2013, 13, 364-386. [CrossRef] 
33. Li, Z.; Du, W.; Zhao, L.; Qian, F. Modeling and optimization of a steam system in a chemical plant containing multiple direct drive steam turbines. Ind. Eng. Chem. Res. 2014, 53, 11021-11032. [CrossRef]

34. Nojavan, S.; Majidi, M.; Najafi-Ghalelou, A.; Ghahramani, M.; Zare, K. A cost-emission model for fuel cell/PV/battery hybrid energy system in the presence of demand response program: $\varepsilon$-constraint method and fuzzy satisfying approach. Energy Convers. Manag. 2017, 138, 383-392. [CrossRef]

(C) 2020 by the authors. Licensee MDPI, Basel, Switzerland. This article is an open access article distributed under the terms and conditions of the Creative Commons Attribution (CC BY) license (http://creativecommons.org/licenses/by/4.0/). 